\title{
Liquid-Liquid Extraction of Some Class $b$ Metal Ions with Thiacrown Ether 1,4,8,11-Tetrathiacyclotetradecane
}

\author{
Eiichi Sekido, Keiitsu SaIto, Yoshiaki Naganuma and Hiroko Kumazakı \\ Department of Chemistry, Faculty of Science, kobe University, Rokkodai, Nada, Kobe 657
}

\begin{abstract}
Liquid-liquid extraction of some class b metals, silver(I), mercury(II), palladium(II) and cadmium(II) .using thiacrown compound, 1,4,8,11-tetrathiacyclotetradecane(TTCT) and picrate( $\left.\mathrm{Pic}^{-}\right)$was stoichiometrically examined. Silver(I) and mercury(II) are extracted into 1,2-dichloroethane as ion-pair compounds, $\left[\mathrm{Ag}(\mathrm{Htct})_{2}\right]^{+\mathrm{Pic}^{-}}$and $[\mathrm{Hg}$ -

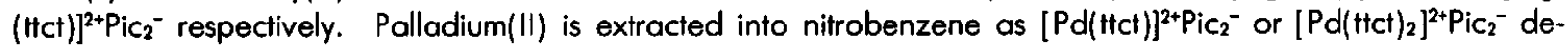
pending on the concentration ratio of TTCT to palladium(II). The extraction constants for silver(I) and mercury(II) and also the distribution coefficient of TTCT in various solvents were determined. The extraction behaviors of these class $b$ metals including copper(I) were compared and discussed in connection with the composition and the conceivable conformation of their extracts.
\end{abstract}

Keywords Liquid-liquid extraction, class b metals, thiacrown ethers, 1,4,8,11-tetrathiacyclotetradecane

The reactions of crown ethers with metal ions, especially alkali ions, have been widely studied in the fields of analytical and co-ordination chemistry. ${ }^{1}$ The chemistry of thiacrown ether, however, has been infrequently studied, especially in analytical chemistry. ${ }^{2,3}$

As thiacrown ethers contain sulfur atoms in the thioether group, they will act as softer Lewis bases than the reagents containing a mercapto group which react with class $a b$ metals as well as class $b$ metals. Consequently, thiacrown ethers will mainly react with softer Lewis acids and class $b$ metals, rather than class $a b$ metals. The difference in the affinities of the thioether group to various groups of metals is particularly interesting in connection with the selective separation of class $b$ metals from class $a$ and $a b$ metals, especially from the first-row transition metals. In fact, it was shown that the perchlorates and picrates of class $b$ metals are selectively extracted with a 1,2-dichloroethane solution of the thiacrown ether, $1,4,8,11$ tetrathiacyclotetradecane(TTCT). ${ }^{4}$ Furthermore, the extraction and spectrophotometric determination of copper and silver with TTCT by the use of an appropriate coloured anion such as Bromocresol Green or picrate has been reported. ${ }^{5}$

Although the separation of class $b$ metals from each other by solvent extraction will be primarily attributed to the difference of their softness, it might be made more selective by the relative sizes of the metal ion and the cavity of the macrocyclic compound, the choice of anion for formation of the ion-pair, and the kind of extraction solvents. In the present study, the stoichiometric extraction behavior of some class $b$ metals such as silver(I), mercury(II), palladium(II) and cadmium(II) into the organic solvent with TTCT were examined. The distribution of TTCT between various organic solvents and aqueous solution was also examined. The differences in the extraction behaviors of the class $b$ metals were discussed in connection with the composition and the conceivable structures of the extracts.

\section{Experimental}

\section{Apparatus}

Extraction was done in a Taiyo $M$ incubator at $25 \pm 0.1^{\circ} \mathrm{C}$. A Seiko SAS-725 atomic absorption spectrophotometer was used to determine the concentration of metals except for mercury(II). A Hiranuma mercury meter HG-1 flameless atomic absorption spectrophotometer was used for the determination of mercury(II). UV and visible absorption spectra were measured with a Hitachi 124 double beam spectrophotometer and Shimadzu self-recording spectrophotometer UV-240. The pH of aqueous phase was measured with a Hitachi-Horiba $\mathrm{H}-5 \mathrm{pH}$ meter.

\section{Reagents}

The reagent, TTCT, was synthesized according to the method by Rosen and Bush ${ }^{6}$ and recrystallized twice from ethanol. Each metal sulfate (analytical-reagent grade) was used to prepare a $1 \times 10^{-2} \mathrm{M}(1 \mathrm{M}=1 \mathrm{~mol}$ $\mathrm{dm}^{-3}$ ) stock solution. The stock solution of each metal except for silver(I) was standardized by complexometric titration. The concentration of silver(I) was 
determined by potentiometric titration. Chloroform was shaken three times with $2 \mathrm{M}$ hydrochloric acid, 2 $M$ sodium hydroxide and water respectively, and then dried over anhydrous sodium sulfate and distilled. 1,2Dichloroethane was shaken three times with $2 \mathrm{M}$ potassium hydroxide and water, dried over calcium chloride, and distilled. Other reagents were of analytical-reagent grade.

\section{Extraction of metal ions}

An aliquot $(10 \mathrm{ml})$ of an aqueous solution containing the metal ion $\left(5 \times 10^{-5} \mathrm{M}\right)$, picrate ion $\left(1 \times 10^{-2} \mathrm{M}\right)$ and acetate buffer $\left(1 \times 10^{-2} \mathrm{M}\right)$, was taken in a $50-\mathrm{ml}$ glass cylindrical tube with a glass stopper. The ionic strength was kept at 0.1 with sodium sulfate. After the addition of $10 \mathrm{ml}$ of a TTCT solution of an organic solvent $\left(1 \times 10^{-3} \mathrm{M}\right)$, the mixture was shaken for $30 \mathrm{~min}$ at 200 strokes $/ \mathrm{min}$ at $25 \pm 0.1^{\circ} \mathrm{C}$. After the mixture was centrifuged for $5 \mathrm{~min}$, the $\mathrm{pH}$ of the aqueous phase was measured and the concentration of the metal ion was measured by atomic absorption spectrometry using the resonance line for the metal. Metal ion concentrations in organic phase were determined as follows: Five $\mathrm{ml}$ of the organic phase was taken and allowed to evaporate. The residue was dissolved with a small amounts of concentrated nitric acid, diluted to the adequate concentration with water, and then the metal ion was determined by atomic absorption spectrometry. The concentration of the picrate ion in the aqueous phase was determined spectrophotometrically at $354 \mathrm{~nm}$.

\section{Distribution coefficient of TTCT}

The distribution coefficient of TTCT was determined by the following procedure. Ten $\mathrm{ml}$ of the aqueous solution containing $0.1 \mathrm{M}$ sodium perchlorate and 0.01 $M$ buffer (acetic acid-sodium acetate) and $10 \mathrm{ml}$ of the organic solvent containing of $5 \times 10^{-3} \mathrm{M}$ TTCT were taken in a $50 \mathrm{ml}$ glass cylindrical tube and shaken for $30 \mathrm{~min}$ with 200 strokes/min at $25 \pm 0.5^{\circ} \mathrm{C}$. After shaking, the solution was centrifuged and the aqueous phase was separated. Five $\mathrm{ml}$ of this aqueous phase and $5 \mathrm{ml}$ of the aqueous solution containing $1.0 \times 10^{-3}$ $M$ silver nitrate standardized with sodium chloride, 0.1 $M$ sodium perchlorate and $0.01 \mathrm{M}$ buffer (acetic acidsodium acetate) were taken in another cylindrical tube and then $10 \mathrm{ml}$ of the organic solvent containing of $5 \times 10^{-3} \mathrm{M}$ TTCT were added. After shaking for $30 \mathrm{~min}$ with 200 strokes/min, the $\mathrm{pH}$ of the aqueous phase was measured, the concentration of silver(I) was measured by atomic absorption spectrophotometry, and then the distribution coefficient was calculated.

\section{Results}

\section{Treatment of equilibrium data}

If the species in the organic phase is represented by $\mathrm{M}(\mathrm{ttct})_{m} \mathrm{Pic}_{n}$, the extraction equilibrium and the

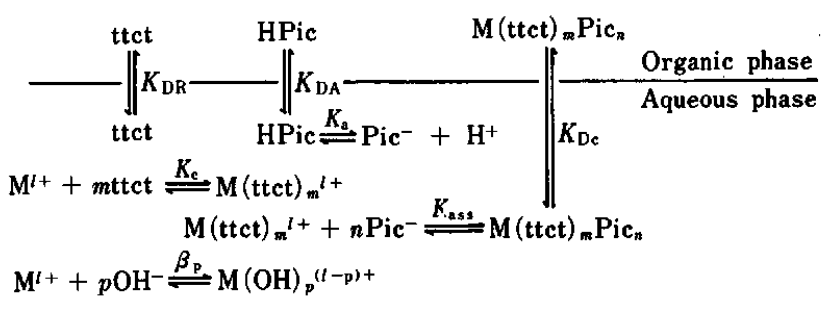

Fig. 1 Equilibria involved in the liquid-liquid extraction for metal-TTCT-Pic system.

extraction constant are given by

$$
\begin{aligned}
& \mathrm{M}^{\prime+}+m \mathrm{ttct}(o)+n \mathrm{Pic}^{-} \stackrel{K_{\mathrm{ex}}}{\rightleftharpoons} \mathrm{M}(\mathrm{ttct})_{m} \mathrm{Pic}_{n}(o), \\
& K_{\mathrm{ex}}=\left[\mathrm{M}(\mathrm{ttct})_{m} \mathrm{Pic}_{n}\right]_{o} /\left[\mathrm{M}^{++}\right][\mathrm{ttct}]_{o}^{m}\left[\mathrm{Pic}^{-}\right]_{n} \cdots \cdots
\end{aligned}
$$

Figure 1 illustrates equilibria involved in this extraction system. Their relevant constants are as follows:

$$
\begin{aligned}
\beta_{\mathbf{p}} & =\left[\mathrm{M}(\mathrm{OH})_{p}\right]^{(I-p)^{+}} /\left[\mathrm{M}^{l+}\right]\left[\mathrm{OH}^{-}\right]^{p} \\
K_{\mathbf{C}} & =\left[\mathrm{M}(\mathrm{ttct})_{m}^{l+}\right] /\left[\mathrm{M}^{\prime+}\right][\mathrm{ttct}]^{m} \\
K_{\text {ass }} & =\left[\mathrm{M}(\mathrm{ttct})_{m} \mathrm{Pic}_{n}\right] /\left[\mathrm{M}(\mathrm{ttct})_{m}^{l+}\right]\left[\mathrm{Pic}^{-}\right]^{n} \\
K_{\mathbf{D c}} & =\left[\mathrm{M}(\mathrm{ttct})_{m} \mathrm{Pic}_{n}\right]_{o} /\left[\mathrm{M}(\mathrm{ttct})_{m} \mathrm{Pic}_{n}\right] \\
K_{\mathrm{DR}} & =[\mathrm{M}(\mathrm{ttct})]_{o} /[\mathrm{ttct}] \\
K_{\mathbf{a}} & =\left[\mathrm{H}^{+}\right]\left[\mathrm{Pic}{ }^{-}\right] /[\mathrm{HPic}] \\
K_{\mathrm{DA}} & =[\mathrm{HPic}]_{o} /[\mathrm{HPic}] .
\end{aligned}
$$

As the extraction proceeded around $\mathrm{pH} 4.0-5.5$, the concentration of picrate ion is almost the same as the initial concentration of picric acid, of which the acid dissociation constant, $K \mathrm{a}$ is $10^{-0.71} .^{7}$ Consequently, the equilibria involving $K$ a can be neglected. If it is assumed that the hydroxo complex is also present along with the free metal ion in the aqueous phase and that the species present in the organic phase is only the ion-pair, $\mathrm{M}(\mathrm{ttct})_{m} \mathrm{Pic}_{n}$, the expression for the distribution ratio of metal ion is given by Eq. 2 .

$$
\begin{aligned}
D_{\mathrm{M}} & =\frac{\left[\mathrm{M}(\mathrm{ttct})_{m} \mathrm{Pic}_{n}\right]_{o}}{\left[\mathrm{M}(\mathrm{ttct})_{m} \mathrm{Pic}_{n}\right]+\left[\mathrm{M}^{l+}\right]+\sum_{p}\left[\mathrm{M}(\mathrm{OH})_{p}^{(l-p)+}\right]} \\
& =\frac{\left[\mathrm{M}(\mathrm{ttct})_{m} \mathrm{Pic}_{n}\right]_{o}}{\left[\mathrm{M}(\mathrm{ttct})_{m} \mathrm{Pic}_{n}\right]+\left[\mathrm{M}^{l+}\right]\left(1+\sum_{p} \beta_{p}\left[\mathrm{OH}^{-}\right]^{p)}\right.}
\end{aligned}
$$

With appropriate substitutions using the above expression for $K \mathrm{C}$, $K_{\mathrm{ass}}, K_{\mathrm{Dc}}$, and $K_{\mathrm{DR}}$, Eq. 2 becomes Eq. 3 .

$$
D_{\mathrm{M}}=\frac{K_{\mathbf{D C}_{\mathrm{c}}}}{\left(1+\sum_{p} \beta_{p}\left[\mathrm{OH}^{-}\right]^{p}\right) / K_{\mathrm{ass}} K_{\mathrm{C}}[\mathrm{ttct}]_{o}^{m}\left[\mathrm{Pic}^{-}\right]^{n}}
$$

and for values $D_{M}<K D_{c}$

$$
D_{\mathrm{M}}=\frac{K_{\mathrm{Dc}} K_{\mathrm{ass}} K_{\mathrm{C}}[\mathrm{ttct}]_{o}^{m}\left[\mathrm{Pic}^{-}\right]^{n}}{K_{\mathrm{DR}}^{m}\left(1+\sum_{p} \beta_{p}\left[\mathrm{OH}^{-}\right]^{p}\right)}
$$

Substitution of the expression for Kex into Eq. 4 leads 
finally to Eq. 5.

$$
D_{\mathrm{M}}=\frac{K_{\mathrm{ex}}[\mathrm{ttct}]_{o}^{m}\left[\mathrm{Pic}^{-}\right]^{n}}{1+\sum_{p} \beta_{p}\left[\mathrm{OH}^{-}\right]^{p}}
$$

which gives the logarithmic expression, Eq. 6 .

$$
\begin{aligned}
\log D_{\mathrm{M}}= & \log K_{\mathrm{ex}}+m \log [\mathrm{ttct}]_{o}+n \log \left[\mathrm{Pic}^{-}\right] \\
& -\log \left(1+\sum_{p} \beta_{p}\left[\mathrm{OH}^{-}\right] p\right)
\end{aligned}
$$

When no hydroxo complex of the metal exists, the last term of Eq. 6 can be neglected and so Eq. 7 is obtained.

$$
\log D_{\mathrm{M}}=\log K_{\mathrm{ex}}+m \log [\mathrm{ttct}]_{o}+n \log \left[\mathrm{Pic}^{-}\right] \quad \ldots
$$

\section{Extraction of silver(I)}

The relationship between the logarithm of distribution ratio $\left(\log D_{\mathrm{Ag}}\right)$ and the logarithm of the ligand concentration in the organic phase at $\mathrm{pH} 5.4$ is shown in Fig. 2(a). Straight lines with the slope of +1.9 and +2.1 for 1,2-dichloroethane and chloroform respectively, were obtained, i.e., $m=2$. A logarithmic plot of $D_{\mathrm{Ag}} v s$. the picrate concentration in the aqueous phase at pH 5.4 is shown in Fig. 2(b). A straight line with the slope of +1 was obtained, i.e., $n=1$. Consequently, we conclude that silver ion is extracted as the ion-pair, [Ag(ttct $\left.)_{2}\right]^{+} \mathrm{Pic}^{-}$. Values of $\log K_{\mathrm{ex}}=11.7 \pm 0.2$ and $10.9 \pm 0.1$ for 1,2-dichloroethane and chloroform, respectively, were calculated from the extraction equilibria data.

\section{Extraction of mercury(II)}

The relationships between the logarithm of distribution ratio $\left(\log D_{H_{g}}\right)$, and the logarithm of ligand concentration in the organic phase at $\mathrm{pH} 4.5$ is shown in Fig. 3(a). A straight line with the slope of +0.8 , which is close to +1 , was obtained, i.e., $m=1$. A plot of $\log D_{\mathrm{Hg}}$ vs. the logarithm of the picrate ion concentration in the aqueous phase at $\mathrm{pH} 4.6$ is shown in Fig. 3(b). A straight line with the slope of +1.9 was obtained, i.e., $n=2$. We conclude that mercury(II) ion
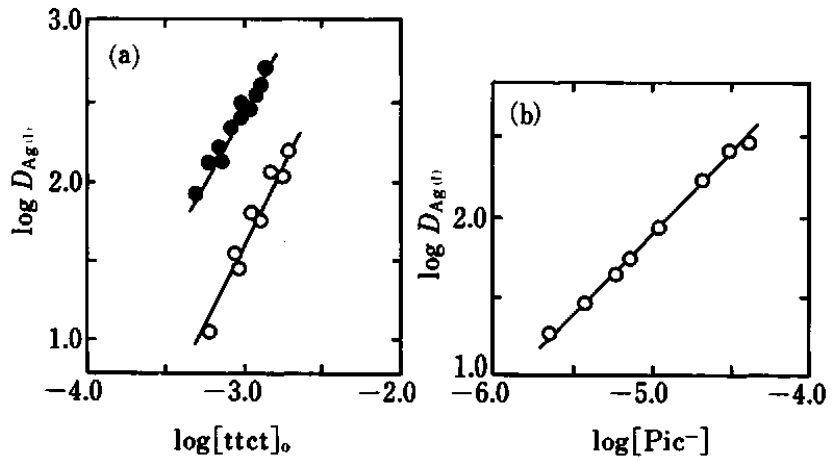

ig. 2 (a) Plots of $\log D_{\mathrm{Ag}(\mathrm{I})}$ vs. $\log [\mathrm{ttct}]_{\mathrm{o}}$ at $\mathrm{pH} 5.4$. O, chloroform; O, 1,2-dichloroethane. (b) Plot of $\log D_{\mathrm{Ag}(\mathrm{I})}$ vs. $\log \left[\mathrm{Pic}^{-}\right]$at $\mathrm{pH}$ 5.4. Initial concentrations: silver(I) $5 \times 10^{-5} \mathrm{M}$, picrate $5 \times 10^{-4} \mathrm{M}$ for (a), TTCT $5 \times 10^{-3} \mathrm{M}$ for (b). Solvent, chloroform. was extracted as the ion-pair, $[\mathrm{Hg}(\mathrm{ttct})]^{2+} \mathrm{Pic}_{2}{ }^{-}$. Mercury(II) ion is so easily hydrolyzed that it is necessary to take account of its hydroxo complexes. The value of $\log K=11.8 \pm 0.1$ in 1,2-dichloroethane was obtained by using $K_{1}=10^{11.03}$ and $K_{2}=10^{10.67}$ for mercury(II) hydroxo complexes at $\mu=0.1$, which were derived from their thermodynamic constants, $K_{1}=$ $10^{11.51}$ and $K_{2}=10^{11.15} .8$

\section{Extraction of palladium (II)}

The relationship between logarithm of the distribution ratio $\left(\log D_{P_{d}}\right)$ and the logarithm of the initial concentration of ligand in the organic phase $\left(\log [\mathrm{ttct}]_{o}\right)$ at pH 4.6 is shown in Fig. 4(a). The straight line with the slope of +1 is obtained on $\log [\text { ttct }]_{o}<-3.7$ $\left([\mathrm{ttct}]_{o} /\left[\mathrm{Pd}^{2+}\right]<4.0\right)$ but it becomes a horizontal line on $\log [\mathrm{ttct}]_{0}>-3.7$. The formation of the palladium TTCT complex cation might be so strong that the extraction of palladium(II) on [ttct $]_{0}>10^{-3.7}$ will be controlled by the ion-pair formation with picrate anion in 1,2-dichloroethane. A similar extraction of palladium(II) with TTCT was also tried by use of
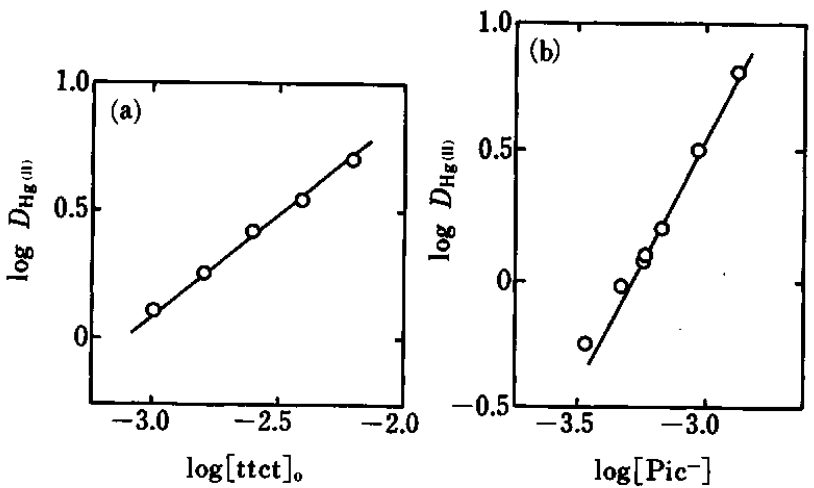

Fig. 3 (a) Plot of $\log D_{\mathrm{Hg}(\mathrm{II})}$ vs. $\log [\mathrm{ttct}]_{\mathrm{o}}$ at $\mathrm{pH} 4.5$. (b) Plot of $\log D_{\mathrm{Hg}(\mathrm{II})}$ vs. $\log \left[\mathrm{Pic}^{-}\right]$at $\mathrm{pH}$ 4.6. Initial concentrations: mercury(II) $1 \times 10^{-5} \mathrm{M}$, picrate $1 \times$ $10^{-3} \mathrm{M}$ for (a), TTCT $5 \times 10^{-3} \mathrm{M}$ for (b). Solvent, 1,2-dichloroethane.
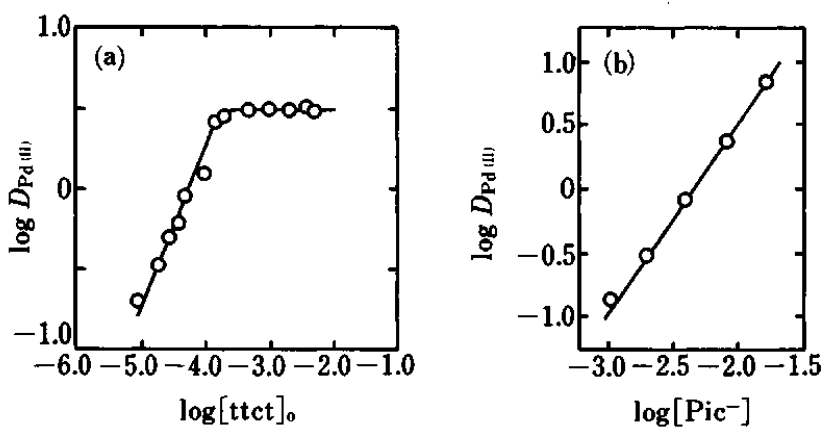

Fig. 4 (a) Plot of $\log D_{\mathrm{Pd}(11)}$ vs. $\log [\mathrm{ttct}]_{0}$ at $\mathrm{pH} 4.6$. (b) Plot of $\log D_{\mathrm{Pd}(\mathrm{II})}$ vs. $\log \left[\mathrm{Pic}^{-}\right]$at $\mathrm{pH}$ 4.6. Initial concentrations: palladium(II) $5 \times 10^{-5} \mathrm{M}$, picrate $1 \times$ $10^{-2} \mathrm{M}$ for (a), TTCT $5 \times 10^{-3} \mathrm{M}$ for (b). Solvent, 1,2-dichloroethane. 

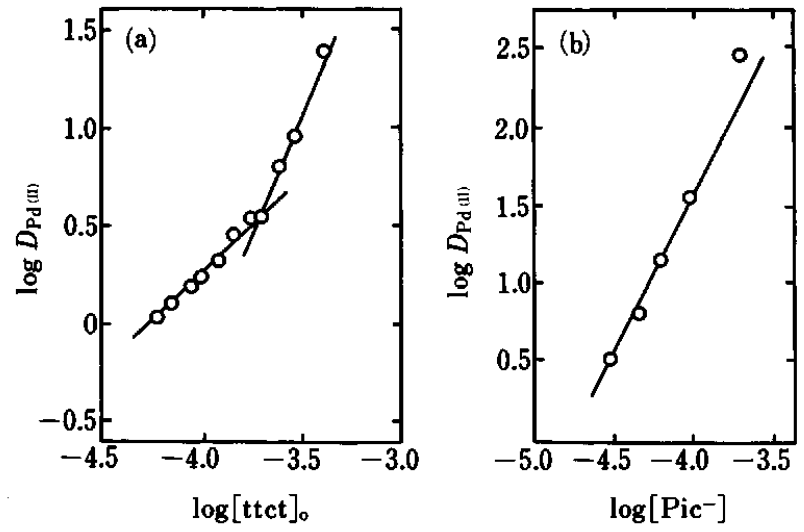

Fig. 5 (a) Plot of $\log D_{\mathrm{Pd}(\mathrm{II})}$ vs. $\log [\mathrm{ttct}]_{\mathrm{o}}$ at $\mathrm{pH} 4.2$. (b) Plot of $\log D_{\mathrm{Pd}(\mathrm{II})}$ vs. $\log \left[\mathrm{Pic}^{-}\right]$at $\mathrm{pH}$ 4.2. Initial concentrations: palladium(II) $5 \times 10^{-5} \mathrm{M}$, picrate $2 \times$ $10^{-2} \mathrm{M}$ for (a), TTCT $2.5 \times 10^{-3} \mathrm{M}$ for (b). Solvent, nitrobenzene.

nitrobenzene in place of 1,2-dichloroethane. The results are shown in Fig. 5(a). A straight line with the slope of +1 was obtained on $\log [\mathrm{ttct}]_{0}=-4.2--3.7$ $\left([\mathrm{ttct}]_{o} /\left[\mathrm{Pd}^{2+}\right]=1.2-4.0\right)$ and one with the slope of +2 on $\log [\mathrm{ttct}]_{o}=-3.7--3.4\left([\mathrm{ttct}]_{o} /\left[\mathrm{Pd}^{2+}\right]=4.0-8.0\right)$. Plots of $\log D$ Pd vs. the logarithm of the concentration of the picrate ion in the aqueous phase at $\mathrm{pH} 4.5$ are shown in Fig. 4(b) and 5(b). A straight line with the slope of +1.5 was obtained in the case of using 1,2dichloroethane as an organic phase, which is not expected from the charge of palladium(II) and its reason is not obvious. However, the plot in the case of nitrobenzene gave a straight line with the slope of +2 as expected. Consequently, it was found that $[\mathrm{Pd}(\mathrm{ttct})]^{2+} \mathrm{Pic}_{2}^{-}$and $\left[\mathrm{Pd}(\mathrm{ttct})_{2}\right]^{2+} \mathrm{Pic}_{2}^{-}$are extracted into nitrobenzene according to the relative concentration of ligand to palladium(II).

\section{Extraction of cadmium(II)}

Very little cadmium(II) was extracted, as reported in the previous paper. ${ }^{4}$ It seems to form no cadmium TTCT cation complex in 1,2-dichloroethane and chloroform. To make sure, we tried to form the cadmium TTCT complex in the acetone-water or ethylacetate-water mixture solution. To the organic solvent-water mixed solution containing both cadmium oxide or sulfate and picric acid or tetraphenyl borate was added the acetone or ethyl acetate solution of TTCT, then the deposit was formed by gentle evaporation or by the addition of hexane. The composites were examined, it was found that the deposits are not cadmium-TTCT complexes but are TTCT and/or cadmium picrate.

\section{Distribution of TTCT between aqueous solution and some organic solvents}

Trace amounts of TTCT are diffucult to determine by conventional analytical methods. Therefore, the fact that TTCT is almost completely extracted as
Table 1 Distribution of TTCT between aqueous and organic solutions

\begin{tabular}{ccccc}
\hline $\mathrm{pH}$ & $\mathrm{C}_{6} \mathrm{H}_{5} \mathrm{NO}_{2}$ & $\mathrm{CH}_{2} \mathrm{ClCH}_{2} \mathrm{Cl}$ & $\mathrm{CHCl}_{3}$ & $\mathrm{CCl}_{4}$ \\
\hline 1.94 & & & 1.96 & \\
3.00 & & & 1.99 & \\
3.44 & & 1.84 & 1.99 & \\
3.55 & & 1.79 & 2.09 & 2.14 \\
3.92 & 1.35 & 1.91 & 1.85 & 1.99 \\
4.40 & 1.46 & 1.79 & & 2.05 \\
4.90 & 1.32 & 1.87 & 1.85 & 2.01 \\
5.48 & 1.04 & 1.84 & 1.96 & 2.07 \\
Mean value & 1.29 & 10.4 & 4.9 & 2.2 \\
Dielectric & 34.8 & 10.9 & & \\
constant & & & & \\
\hline
\end{tabular}

[Ag(ttct) $]^{+} \mathrm{Pic}^{-}$into an organic solvent was adopted to the determination of TTCT. The distribution ratios of TTCT between aqueous solutions and organic solvents such as nitrobenzene, 1,2-dichloroethane, chloroform and carbon tetrachloride are shown in Table 1. The values of the distribution ratio of TTCT for each solvent are independent to $\mathrm{pH}$ in the range of 2 to 6 as expected, and the mean value of distribution coefficient for each solvent increases in the order of nitrobenzene $<1,2$-dichloroethane $<$ chloroform $<$ carbon tetrachloride, which is the decreasing order of their dielectric constant values. It is obvious that the ligand, TTCT, is more soluble in the more non-polar solvents.

\section{Discussion}

\section{Composition of metal TTCT complexes and their} estimated configurations

The formation of the metal TTCT complex is primarily governed by the softness of the metal ion bonding with sulfur ligand atoms in thioether type ( $R$ S-R). The configuration of the formed complex depends on 1) the relative size of the metal to the cavity of the ligand, 2) the favourable stereochemistry for the metal ion and the relative position of four sulfur atoms and 3) the concentration ratios of the metal and the ligand. Moreover, extraction of the metal is associated with the formation of the ion-pair between the metal TTCT complex cation and the picrate anion, and also with the affinity of the formed ion-pair to the organic solvent. In Table 2, the composition of the extracted metal TTCT complexes is summarized and also some properties of the metals are given in order to discuss the formation of metal complexes and their configurations.

Studies of the solid-state structure and the solution thermodynamic stability for copper(II) complexes with the cyclic tetrathia ether ligand, $[n] \operatorname{ane} S_{4}(n=12-16)$, suggested that the ligand [14]aneS $S_{4}$, that is TTCT, provides an optimum fit for planar co-ordination around copper(II). ${ }^{9,10}$ According to the molecular structure of $\mathrm{Cu}^{\mathrm{II}}(\mathrm{ttct})\left(\mathrm{ClO}_{4}\right)_{2},{ }^{11}$ the four sulfur donor 
Table 2 Composition of class $b$ metals-TTCT-Pic complexes with some properties of these metal ions

\begin{tabular}{|c|c|c|c|c|c|}
\hline Metals & $\begin{array}{l}\text { Classification of } \\
\text { metals by Arhland }\end{array}$ & $\alpha$ Value $^{\mathfrak{a}}$ & $\underset{\AA}{\text { Covalent radius }}$ & $\begin{array}{l}\text { Composition of } \\
\text { extracted TTCT complex }\end{array}$ & $\begin{array}{l}\text { Favorable structure } \\
\text { of metal complex }\end{array}$ \\
\hline $\mathbf{C u}(\mathbf{I})$ & $b$ & 3.92 & $1.28^{b}$ & \multirow{6}{*}{$\begin{array}{l}{[\mathrm{Cu}(\mathrm{ttct})]^{+} \mathrm{Pic}^{-} \mathrm{e}} \\
{\left[\mathrm{Ag}(\mathrm{ttct}){ }_{2}\right]^{+} \mathrm{Pic}^{-} \mathrm{e}} \\
{[\mathrm{Hg}(\mathrm{ttct})]^{2+} \mathrm{Pic}_{2}^{-} \mathrm{e}} \\
{[\mathrm{Pd}(\mathrm{ttct})]^{2+} \mathrm{Pic}_{2}^{-} \mathrm{f}} \\
{\left[\mathrm{Pd}(\mathrm{ttct})_{2}\right]^{2+} \mathrm{Pic}_{2}^{-} \mathrm{f}} \\
\mathrm{No} \text { formation } \\
{[\mathrm{Cu}(\mathrm{ttct})]^{2+}\left(\mathrm{ClO}_{4}^{-}\right)_{2}{ }^{\mathrm{d}}}\end{array}$} & \multirow{6}{*}{$\begin{array}{l}\text { Tetrahedral } \\
\text { Linear } \\
\text { Tetrahedral } \\
\text { Planar or } \\
\text { tetragonal } \\
\text { Tetrahedral } \\
\text { Tetragonal }\end{array}$} \\
\hline $\mathbf{A g}(\mathrm{I})$ & $\boldsymbol{b}$ & 3.60 & $1.52 \mathrm{c}$ & & \\
\hline $\mathbf{H g}(\mathrm{II})$ & $b$ & 5.83 & $1.48 \mathrm{c}$ & & \\
\hline $\operatorname{Pd}(\mathbf{I I})$ & $\boldsymbol{b}$ & 5.33 & $1.31^{\mathrm{c}}$ & & \\
\hline $\mathrm{Cd}(\mathbf{I I})$ & $b$ & 1.66 & $1.48^{\mathrm{c}}$ & & \\
\hline $\mathrm{Cu}(\mathrm{II})$ & $a b$ & 1.64 & $1.30^{d}$ & & \\
\hline
\end{tabular}

a. Ref. 14.

b. Derived value from $\mathrm{Cu}(\mathrm{I})-\mathrm{S}$ bond length, $2.39 \AA$ reported in Ref. 13 .

c. Ref. 12.

d. Derived value from $\mathrm{Cu}(\mathrm{II})-\mathrm{S}$ bond length, $2.34 \AA$ reported in Ref. 11.

e. In 1,2-dichloroethane.

f. In nitrobenzene.

atoms lie in a square-planar arrangement around the central copper(II) with copper-sulfur bond lengths in the range of 2.30 to $2.31 \AA$. If the covalent radius of sulfur atom is estimates to $1.04^{12}$, the covalent radius of copper(II) is $1.26 \AA$ : this value will be the optimum covalent radius of a metal fitting in the cavity of the TTCT ligand. This radius of copper(II), however, is a little shorter than its covalent radius, $1.30 \AA$, cited in Table 2. The copper(II)-sulfur bond may be shortened, owing to the double bond character induced by $\pi$ back-donation from copper(II) to sulfur atom. If the values of the covalent radii of class $b$ metals shown in Table 2 are inspected, taking account a shorterning of the bond length by the some double bond formation for each class $b$ metal, copper(I) and palladium(II) as well as copper(II) might be accomodated in the cavity of TTCT ligand. On the other hand, silver(I), mercury(II) and cadmium(II) will be too large to accomodate in the cavity, even if shortening of these metal-sulfur bonds by $\pi$ back-donation is considered.

It was previously reported that copper(I) is almost completely extracted (on E\%>99.4) as 1:1 copper TTCT complex, [Cu(ttct)] ${ }^{+} \mathrm{Pic}^{-}$into 1,2-dichloroethane or chloroform. ${ }^{4}$ The average copper(I)-sulfur bond length in the complex, [Cu(ttct) $]^{+} \mathrm{ClO}_{4^{-}}$, is $2.32 \AA:^{13}$ this value is almost identical with that of $2.303 \AA$ found in the corresponding copper(II) complex. Consequently, copper(I) must be able to fit in the cavity of TTCT ligand. However, in the solid state of the complex, $[\mathrm{Cu}(\mathrm{ttct})]^{+} \mathrm{ClO}_{4}^{-}$, the tetrahedral arrangement which copper(I) favours strongly is accomplished by three sulfur atoms from one TTCT ligand molecule and a fourth sulfur atom from an adjacent TTCT molecule; therefore, a 3:1-coordinate polynuclear copper(I) complex is formed. ${ }^{13}$ Although it is not obvious whether such a configuration holds or not in organic solvents, it is likely that the fourth co-ordination site of copper(I) is replaced by the solvent molecule, holding on the tetrahedral structure, and that the mononuclear copper(I) TTCT complex is highly extracted in organic solvents.

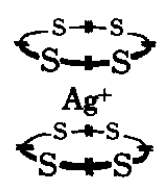

(b)

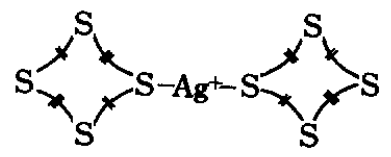

(a)

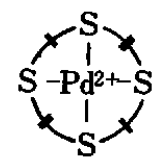

(c)

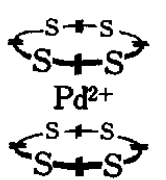

(d)

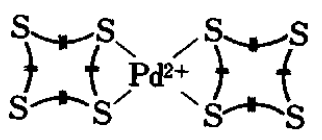

(e)
Fig. 6 Schematic representation of possible configuration of silver(I) and palladium(II) TTCT .complex cations.

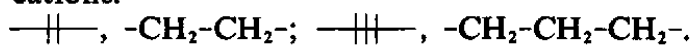

The composition of the extracted silver TTCT complex, $\left[\mathrm{Ag}(\mathrm{ttct})_{2}\right]^{+} \mathrm{Pic}^{-}$, is different from that of the copper(I) TTCT complex, [Cu(ttct) $]^{+} \mathrm{Pic}^{-}$. The cavity of the TTCT ligand will not be enough to accomodate the silver(I) which is much larger than copper(I). Moreover, silver(I) favours a linear type complex. From these reason, TTCT may act as monodentate ligand in its exo form ${ }^{15}$ and then silver(I) may form a $1: 2$ linear complex rather than a sandwitch complex as depicted in Fig. 6(a) and (b), respectively.

Mercury(II) is extracted as the $1: 1$ complex, $[\mathrm{Hg}(\mathrm{ttct})]^{2+} \mathrm{Pic}_{2}^{-}$, whose composition is different from 1:2 silver complex, $\left[\mathrm{Ag}(\mathrm{ttct})_{2}\right]^{+} \mathrm{Pic}^{-}$The mercury(II)sulfur covalent bond will be rather strong, as the $\alpha$ value of mercury(II) is the largest among the class $b$ metals. Moreover, the size of mercury(II) is so large that mercury(II) will not be able to accomodate in the cavity of TTCT ligand. Therefore, it is supposed that the $1: 1$ complex in organic solvents will hold a squarepyramidal configuration in its solid-state ${ }^{16}$, in which four sulfur atoms will occupy the basal plane and fifth site will be occupied by the solvent molecule or picrate ion. 
The size of palladium(II) seems to be on the border line of fitting or not in the cavity of TTCT ligand. For the $1: 1$ complex, $[\mathrm{Pd}(\mathrm{ttct})]^{2+} \mathrm{Pic}_{2}^{-}$, extracted into nitrobenzene under relatively low concentration of the ligand, palladium(II) will lie on the plane or little above the plane formed with four sulfur donor atoms (Fig.

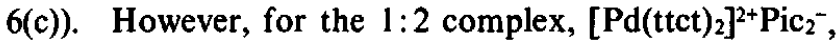
extacted into nitrobenzene under relatively high concentration of the ligand, the planar conformation in which TTCT ligands on the exo form will function as the bidentate ligands as depicted in Fig. 6(e) rather than the sandwitch conformation (Fig. 6(d)).

As shown in Table 2, cadmium(II) is classified as a class $b$ metal, but its softness, which is represented by its $\alpha$ value, is much less than those of other class $b$ metals such as silver(I), copper(I), mercury(II) and palladium(II). Moreover, the covalent radius of cadmium(II), $1.48 \AA$ is too larger to accomodate in the cavity of TTCT ligand. Thus cadmium(II) seems not to form its TTCT complex cation, and hence will not be extracted into organic solvents.

\section{References}

1. I. M. Kolthoff, Anal. Chem., 51, 1R - 22R (1979).

2. D. Sevdic and H. Mieder, J. Inorg. Nucl. Chem., 39, 1403, 1409 (1977).

3. D. Sevic, L. Fekete and H. Mieder, J. Inorg, Nucl. Chem., 42, 885 (1980).

4. K. Saito, Y. Masuda and E. Sekido, Anal. Chim. Acta,
151, 447 (1984).

5. K. Saito, Y. Masuda and E. Sekido, Bull. Chem. Soc. Jpn., 57, 189 (1984).

6. W. Rosen and D. H. Busch, J. Am. Chem. Soc., 91, 4694 (1969).

7. J. F. J. Dippy, S. R. C. Hughes and J. W. Laxton, J. Chem. Soc., 1956, 2995.

8 .J. Bjerrum, G. Schwarzenbach and L. G. Sillen, "Stability Constants of Metal Ion Complexes with Solubility Products of Inorganic Substances" Part II, The Chemical Society, London (1957).

9. V. B. Pett, L. L. Diaddario Jr., E. R. Dockal, P. W. Corfield, C. C. Milton, D. Glick, L. A. Ochrymowycz and D. B. Rorabacher, Inorg. Chem., 22, 3661 (1983).

10. L. S. W. L. Sokol, L. A. Ochrymowycz and D. B. Rorabacher, Inorg. Chem., 20, 3189 (1981).

11. M. D. Glick, D. P. Gavel, L. L. Diaddario, Jr. and D. B. Rorabacher, Inorg Chem., 15, 1190 (1976).

12. L. Pauling "The Nature of the Chemical Bond" 3rd ed., Chapter 7, Cornell University Press, Ithaca, N. Y., (1960).

13. E. R. Dockal, L. L. Diaddario and M. D. Rorabacher, J. Am. Chem. Soc., 99, 4530 (1977).

14. S. Yamada and M. Tanaka, J. Inorg. Nucl. Chem., 37, 587 (1975).

15. R. E. DeSimone and M. D. Glick, J. Am. Chem. Soc., 98, 768 (1976).

16. N. W. Alcock, N Herron and P. Moore, J. Chem. Soc. Dalton Trans., 1978, 394.

(Received May 27, 1985)

(Accepted July 19, 1985) 